\title{
Geotechnical Properties of Gopalganj Sub-soil in Bangladesh
}

\author{
Sabbir-Ul-Islam ${ }^{1}$, Md. Ebrahim Shaik ${ }^{2, *}$ \\ ${ }^{1}$ Department of Civil Engineering, Bangladesh University of Engineering \& Technology, Dhaka, Bangladesh \\ ${ }^{2}$ Department of Civil Engineering, Khulna University of Engineering \& Technology, Khulna, Bangladesh
}

\section{Email address:}

sabbirulislamce2k10@gmail.com (Sabbir-Ul-Islam), ebrahimkuet82@gmail.com (Md. E. Shaik)

${ }^{*}$ Corresponding author

\section{To cite this article:}

Sabbir-Ul-Islam, Md. Ebrahim Shaik. Geotechnical Properties of Gopalganj Sub-soil in Bangladesh. Landscape Architecture and Regional Planning. Vol. 5, No. 2, 2020, pp. 27-32. doi: 10.11648/j.larp.20200502.12

Received: January 15, 2020; Accepted: January 29, 2020; Published: May 29, 2020

\begin{abstract}
Gopalganj town is situated on southern region of Bangladesh which is near to the coastal region. The sub-soil in this region is formed by the alluvial deposits from different rivers. For economical and effective selection and design of foundation, it is very important for geotechnical engineers to go for detailed investigations of geotechnical properties of sub-soil. Some soil samples were collected from Gopalganj town area and tested in the Geotechnical laboratory of Khulna University of Engineering and Technology (KUET), Khulna to determine the geotechnical properties of soil and other data were collected from soil investigation reports prepared by CRTS (Civil), KUET, Khulna. The sub-soil is composed of fine grained soils of soft to medium stiff consistency up to $30 \mathrm{ft}$ depth from the existing ground surface and the soil predominantly consists of course grained soils of medium to very dense compactness below $30 \mathrm{ft}$ depth. For the Gopalganj sub-soil the values of unit weight, specific gravity, natural moisture content, liquid limit, plastic limit, unconfined compressive strength, cohesion, angle of internal friction, compression index and natural void ratio varies from $13.23 \mathrm{kN} / \mathrm{m}^{3}$ to $14.21 \mathrm{kN} / \mathrm{m}^{3}, 2.68$ to $2.73,32 \%$ to $65 \%, 33 \%$ to $60 \%, 26 \%$ to $48 \%, 5 \mathrm{kPa}$ to $90 \mathrm{kPa}, 0.93 \mathrm{kPa}$ to $8.20 \mathrm{kPa}, 27^{\circ}$ to $38^{\circ}, 0.16$ to 1.0 and 0.83 to 2.30 respectively. For the construction of low rise building, shallow foundation may be used with or without replacing the soil layer below the foundation with sand having proper compaction. For medium to high rise buildings, pile or piled raft foundations may be used that penetrate through the soils of very soft to stiff consistency to deeper strata of dense compactness located at 30 to $40 \mathrm{ft}$ depth from the ground surface. The results obtained in this study will be useful for those owners who are interested to construct building without soil investigation.
\end{abstract}

Keywords: Foundation, Geotechnical, Fine Grained, Unconfined Compressive Strength, Sub Soil

\section{Introduction}

The clear and accurate concept on the geotechnical properties of the sub-soil of any project site is most essential for the safe and economical design of foundation. So that, after construction of the concerned structure, it would remain safe and stable through its service period. It is very important for the success of any project related to the construction of civil engineering infrastructures [1-3].

Gopalganj town is a district head quarter. In the recent years, several new buildings as well as large development projects have been and are being constructed including construction of hospitals, university, high rise buildings, bridges, overhead water tanks, heavy structures, many commercial buildings, industries, stadium, power station, towers, oil storage tanks etc. For the construction of these projects, different types of foundation systems are adopted based on the sub-soil profile, engineering properties of soil, building types and purpose of constructing the building.

Gopalganj town is situated on southern region of Bangladesh. It is also very near to the coastal region. The soil in this region is formed by the alluvial deposits from different rivers. For these reasons, the soil of this town is soft to medium stiff, compressible having organic matter in some of the sites with low to medium bearing capacity.

Previous researchers are investigated that most of the soil in coastal region consists by sandy soil [4]. Amin et al presented the index properties, unconfined compressive strength, shear strength parameters and attempted to correlate 
geotechnical properties of coastal soils for the districts of Barisal, Bhola, Noakhali and Sandwip [5]. Hussain (1980) studied the engineering properties of sub-soil in the coast of Bangladesh including the districts of Barisal, Bhola, Patuakhali, Khulna and Noakhali. He developed some empirical relationships between compression index and liquid limit, compression index and natural water content and compression index and initial void ratio and suggested some guide lines on foundation in the coastal area of Bangladesh [6]. The river water in Gopalganj district is seriously threatened by salinity [7].

The effect of geotechnical properties of soil on structure is important to know an engineer for analysing the foundations [8]. At costal region, sub-soil properties are very important for construction of road works [9]. It can reduce the danger effects of post construction problems [10]. If sub soil properties of construction materials are not good bad road accident are occurred [11, 12]. Geotechnical engineer are obliged to determine the geotechnical properties of soil and applies lots practically [13-15].

The main objectives of the study are as follows:

a) To study the sub-soil conditions and geotechnical properties of different locations of Gopalganj town.

b) To find out the variation of different geotechnical properties.

c) To construct an approximate soil profile of different sites.

\section{Methodology}

In this investigation, both disturbed and undisturbed soil samples were collected from selected sites of Gopalganj town for the field investigation and laboratory tests. Sub-soil investigation reports of seven sites of Gopalganj town containing ninety borehole data were collected from Consultancy Research and Testing Services (CRTS), Department of Civil Engineering, KUET, Khulna. The sites selected for the study are shown in Figure 1.
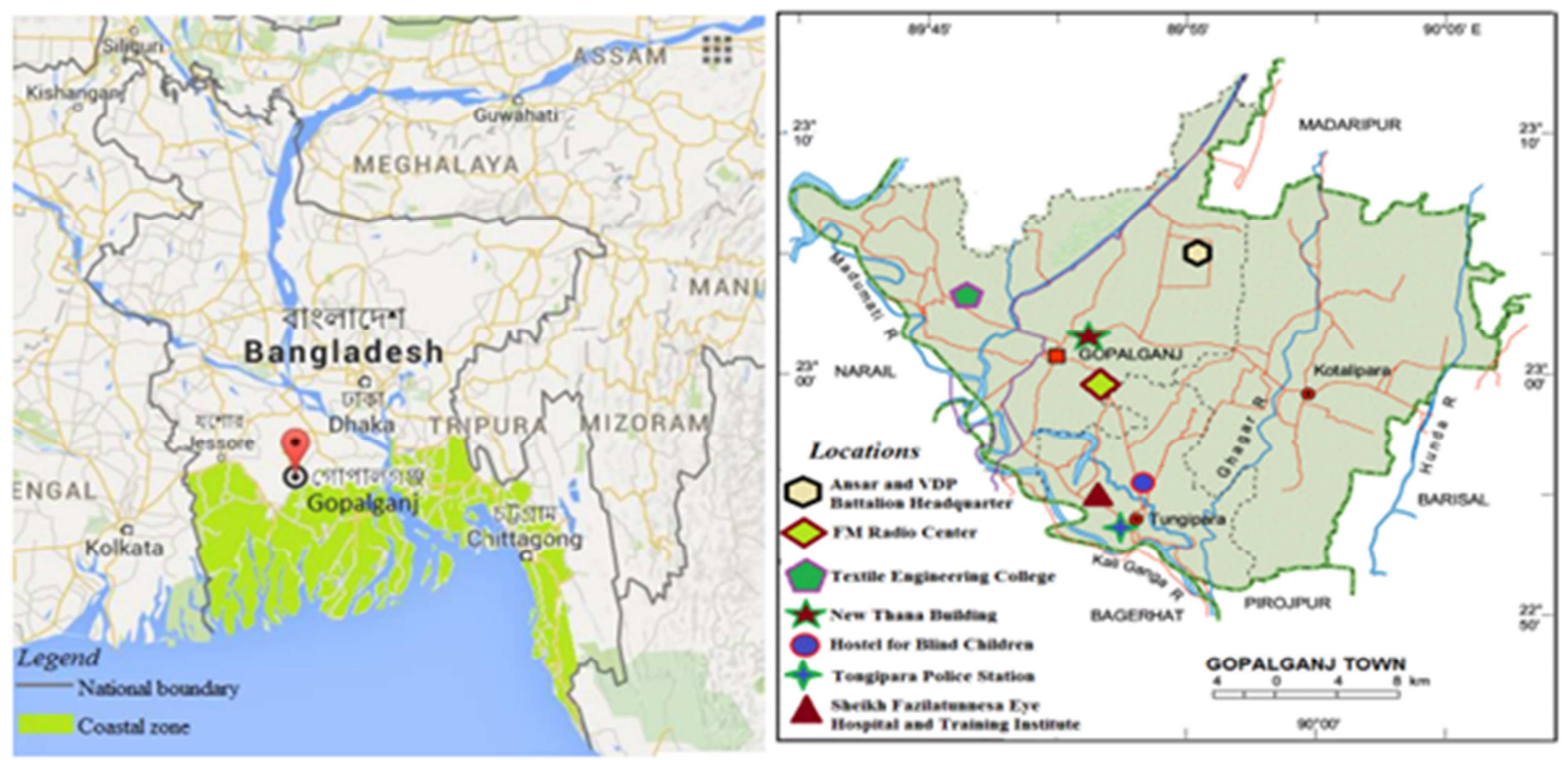

Figure 1. Location of Gopalganj town in Bangladesh map and Location of study sites in Gopalganj town map.

The flow chart of the procedure of the works is given below:

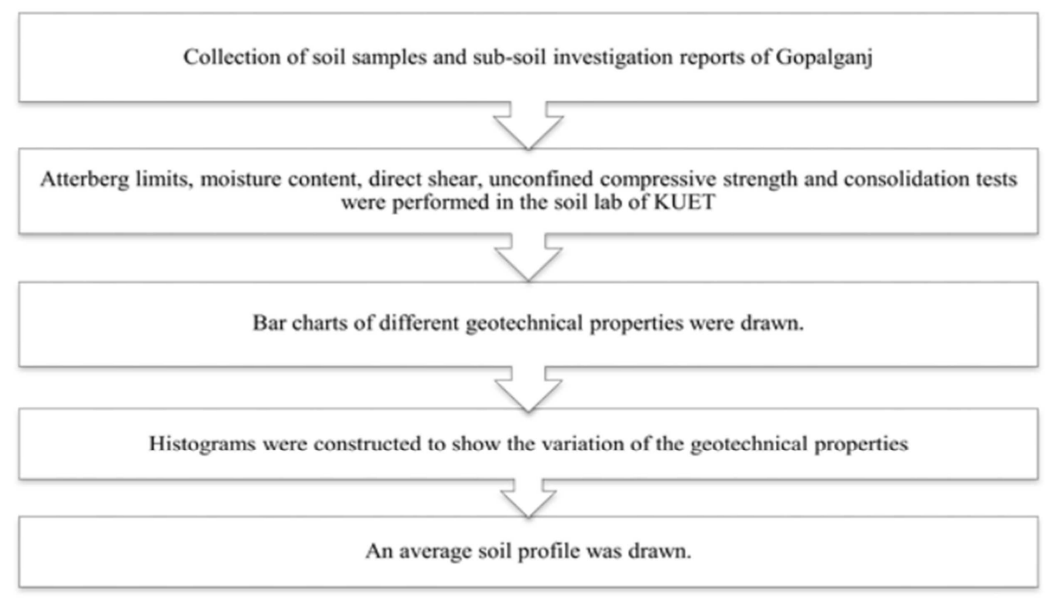

Figure 2. Flow chart (procedure). 
Table 1. $N$ value of different bore holes of a typical site (Gopalganj Textile Engineering College).

\begin{tabular}{|c|c|c|c|c|c|c|c|c|c|c|c|}
\hline \multirow{2}{*}{ Depth (ft) } & \multicolumn{11}{|c|}{ N Value } \\
\hline & BH 1 & BH 2 & BH 3 & BH 4 & BH 5 & BH 6 & BH 7 & BH 8 & BH 9 & BH 10 & Avg \\
\hline 5 & 2 & 2 & 2 & 3 & 3 & 3 & 3 & 4 & 3 & 3 & 2.8 \\
\hline 10 & 1 & 1 & 4 & 1 & 2 & 4 & 3 & 6 & 6 & 5 & 3.3 \\
\hline 15 & 2 & 3 & 3 & 2 & 2 & 3 & 4 & 4 & 5 & 5 & 3.3 \\
\hline 20 & 4 & 5 & 5 & 4 & 2 & 4 & 3 & 3 & 5 & 6 & 4.1 \\
\hline 25 & 4 & 5 & 8 & 4 & 4 & 6 & 6 & 9 & 8 & 7 & 6.1 \\
\hline 30 & 6 & 7 & 10 & 5 & 4 & 8 & 7 & 10 & 11 & 8 & 7.6 \\
\hline 35 & 11 & 9 & 9 & 6 & 7 & 12 & 11 & 12 & 11 & 11 & 9.9 \\
\hline 40 & 11 & 10 & 10 & 7 & 9 & 15 & 14 & 15 & 13 & 14 & 11.8 \\
\hline 45 & 14 & 12 & 12 & 12 & 8 & 13 & 12 & 16 & 13 & 16 & 12.8 \\
\hline 50 & 20 & 17 & 15 & 15 & 8 & 12 & 15 & 18 & 14 & 31 & 16.5 \\
\hline 60 & 62 & 21 & 29 & 88 & 22 & 15 & 17 & 16 & 20 & 28 & 31.8 \\
\hline 70 & 30 & 13 & 33 & 51 & 87 & 18 & 28 & 30 & 27 & 24 & 34.1 \\
\hline 75 & 25 & 28 & 28 & 40 & 39 & 46 & 40 & 28 & 28 & 22 & $32.4 \mathrm{zdh}$ \\
\hline
\end{tabular}

\section{Illustrations}

\subsection{Standard Penetration Number, $N$}

The sub-soil consists of fine-grained soils up to an average depth of $30 \mathrm{ft}$ from the existing ground surface. The average $\mathrm{N}$ value ranges from 2 to 11 (consistency: soft to stiff). Below 30ft depth, the soil predominantly consists of coarse-grained soils, encountered in most of the bore holes, having $\mathrm{N}$ value from 7 to 118 . $\mathrm{N}$ values of different bore holes of a typical site are shown in Table 1.

For each site, the average standard penetration number $(\mathrm{N}$ value) is determined by averaging the $\mathrm{N}$ value of all the bore holes of that site. Finally averaging the $\mathrm{N}$ value of all the sites the average $\mathrm{N}$ value of Gopalganj sub-soil is obtained. Figure 3 shows the average $\mathrm{N}$ value of all the sites vs depth.

\subsection{Unit Weight, $\gamma$}

The unit weight of the investigated soil samples varies from $13.23 \mathrm{kN} / \mathrm{m}^{3}$ to $14.21 \mathrm{kN} / \mathrm{m}^{3}$.

\subsection{Specific Gravity, Gs}

The specific gravity of the investigated samples varies from 2.68 to 2.73 .

\subsection{Natural Void Ratio}

The value of natural void ratio of the investigated soil samples varies from 0.83 to 2.30 .

The variation of unit weight, specific gravity and natural void ratio of different bore holes of a typical site is shown in Figure 4.

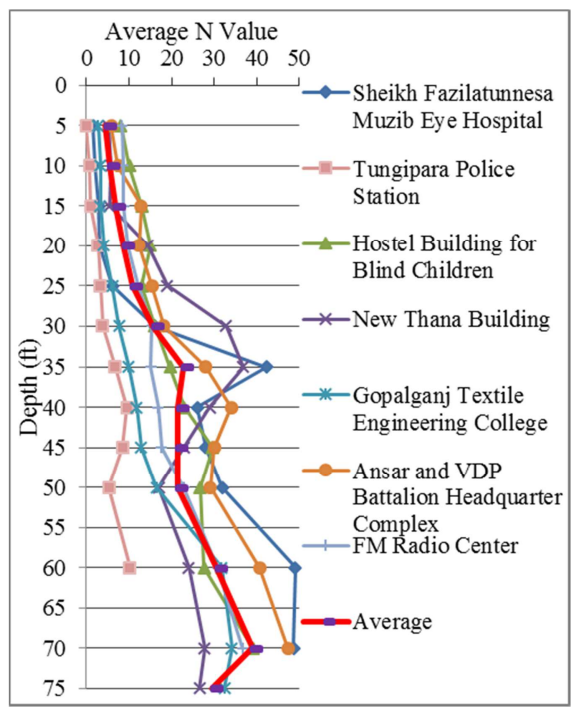

Figure 3. Average $N$ value of all the sites vs depth.

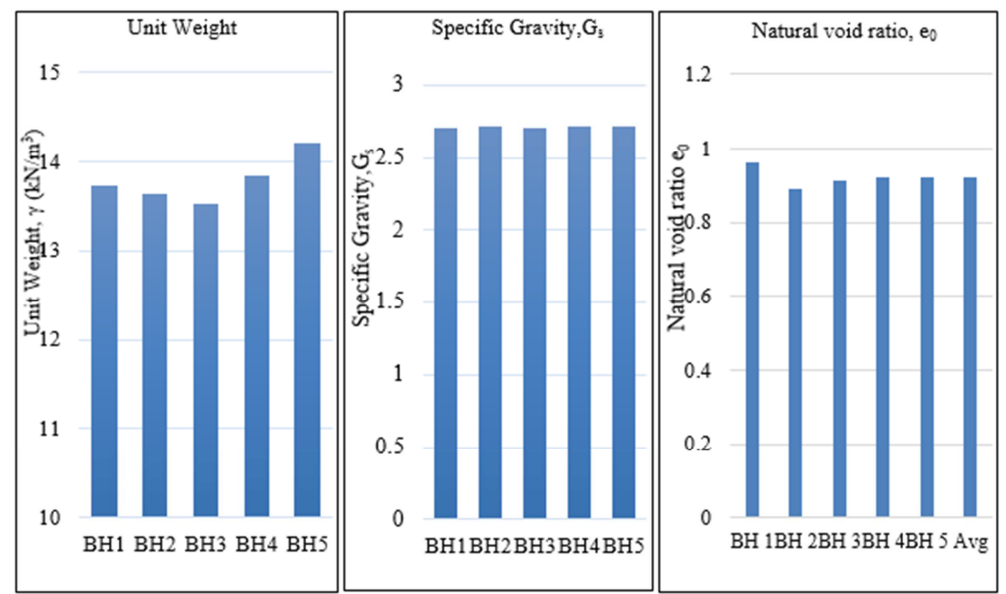

Figure 4. The variation of unit weight, specific gravity and natural void ratio of different bore holes of a typical site (New Thana Building, Sadar Thana, Gopalganj. 


\subsection{Atterberg Limits}

The liquid limit and plastic limit of the investigated soil samples as recorded from Atterberg limit test ranges from $33 \%$ to $98 \%$ and $26 \%$ to $81 \%$. The variation of liquid limit and plastic limit of different bore holes at different sites are shown in Figure 5 .

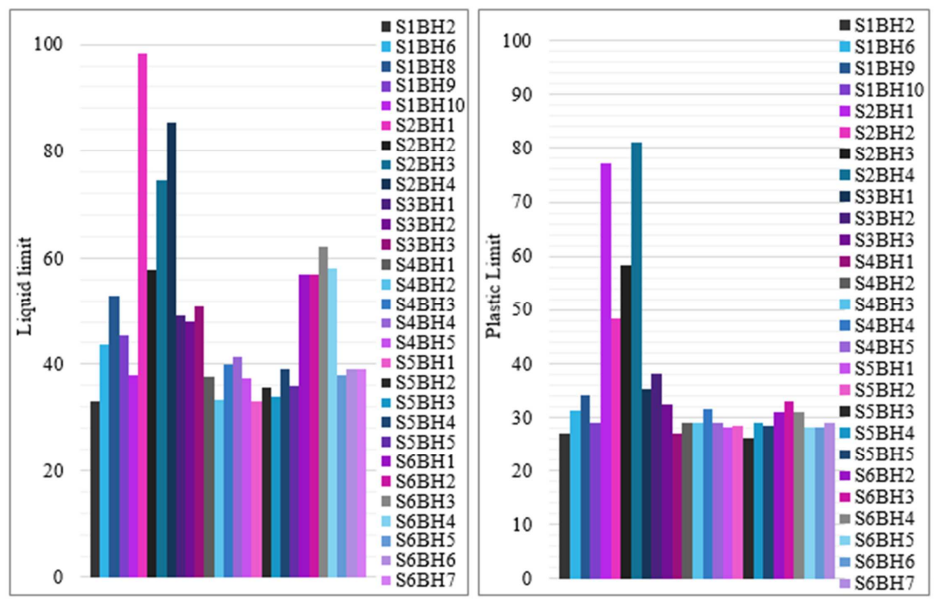

Figure 5. The histograms showing the variation of liquid limit and plastic limit of different bore holes at different sites at $5 f t$ depth.

\subsection{Unconfined Compressive Strength, $q_{u}$}

The value of unconfined compressive strength as reported from unconfined compression test varies from $5 \mathrm{kPa}$ to $90 \mathrm{kPa}$. The variation of unconfined compressive strength at $5 \mathrm{ft}$ depth is shown in Figure 6.

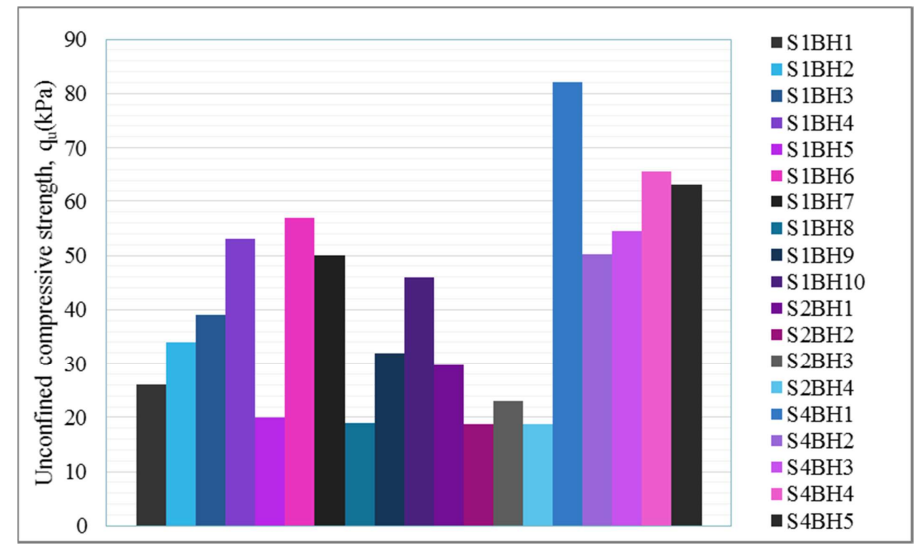

Figure 6. Histogram showing the variation of unconfined compressive strength of different bore holes at different sites at $5 f t$ depth.

\subsection{Cohesion, $c$}

The cohesion of the investigated samples from direct shear test varies from $0.93 \mathrm{kPa}$ to $8.20 \mathrm{kPa}$ as shown in Figure 7 . The value of cohesion of site 7 (FM Radio Centre) is the lowest.

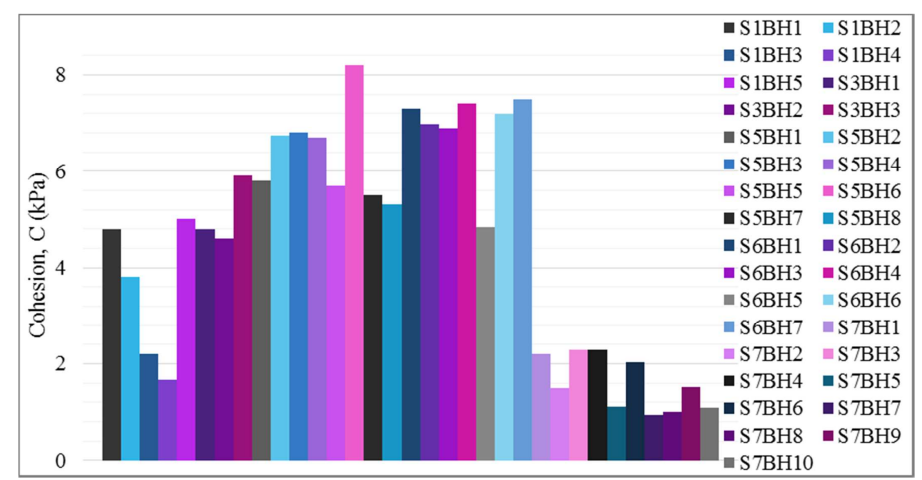

Figure 7. Histogram showing the variation of cohesion of different bore holes at different sites at 25ft depth. 


\subsection{Angle of Internal Friction, $\phi^{\circ}$}

The angle of internal friction $\left(\phi^{\circ}\right)$ of the investigated samples as reported from direct shear test varies from $27^{\circ}$ to $38^{\circ}$ which is shown in Figure 8.

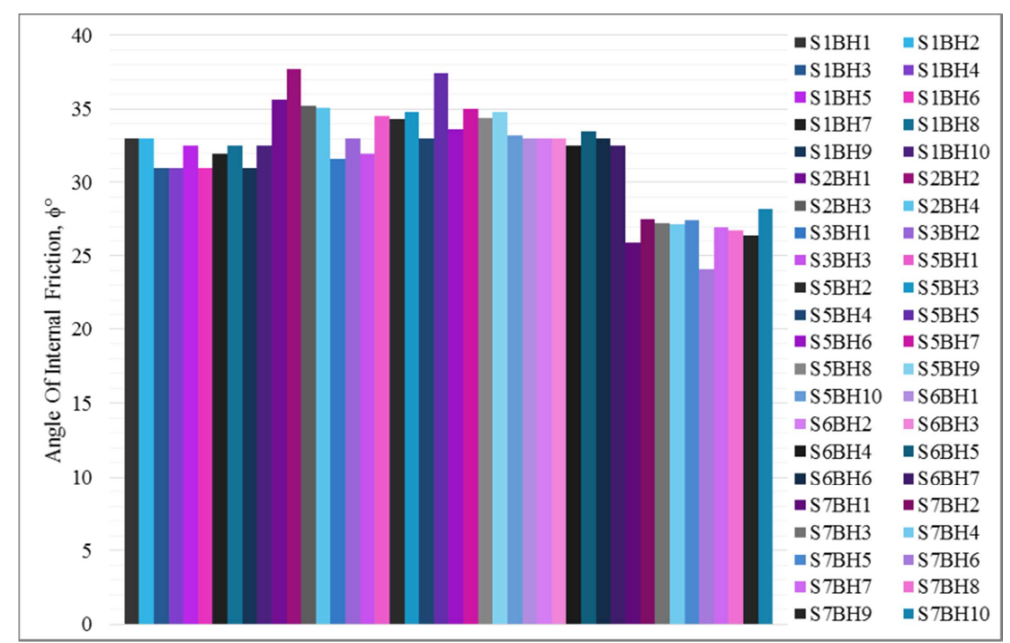

Figure 8. Histogram showing the variation of angle of internal friction of different bore holes at different sites at 25ft depth.

\subsection{Compression Index, $C c$}

The compression index of the investigated soil samples as reported from consolidation test varies from 0.16 to 1.0 shown in Figure 9. Generally fine-grained soils have a greater degree of compressibility. The sub soil of site2 (Tungipara Police Station) has the highest compression index of 1.0 indicating larger settlement.

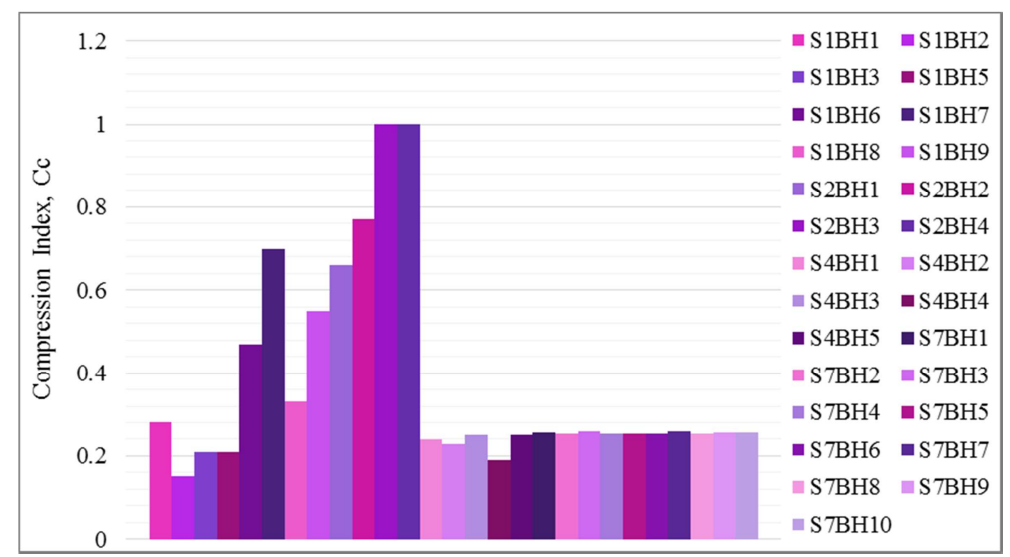

Figure 9. Histogram showing the variation of compression index of different bore holes at different sites at $5 f t$ depth.

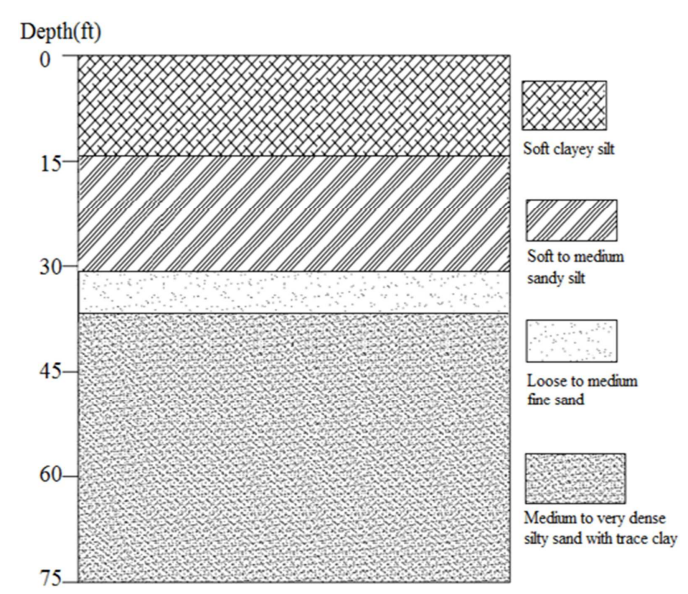

Figure 10. Soil profile of Gopalganj sub-soil.

\subsection{Soil Profile of Gopalganj Sub-soil}

The sub-soil consists of soft clayey silt up to an average depth of $15 \mathrm{ft}$. from the existing ground surface. Sandy silt layer is encountered below $15 \mathrm{ft}$ depth having stiff to very stiff consistency. Medium to very dense silty sand layer generally exists below $30 \mathrm{ft}$ depth.

\section{Conclusions}

For the Gopalganj sub-soil the values of unit weight, specific gravity, natural moisture content, liquid limit, plastic limit, unconfined compressive strength, cohesion, angle of internal friction, compression index and natural void ratio varies from $13.23 \mathrm{kN} / \mathrm{m}^{3}$ to $14.21 \mathrm{kN} / \mathrm{m}^{3}, 2.68$ to $2.73,32 \%$ to 
$65 \%, 33 \%$ to $60 \%, 26 \%$ to $48 \%, 5 \mathrm{kPa}$ to $90 \mathrm{kPa}, 0.93 \mathrm{kPa}$ to $8.20 \mathrm{kPa}, 27^{\circ}$ to $38^{\circ}, 0.16$ to 1.0 and 0.83 to 2.30 respectively.

The sub-soil of Gopalganj town is composed of fine grained soils of very soft to stiff consistency up to $30 \mathrm{ft}$ depth from the ground surface and the soil predominantly consists of course grained soils of medium to very dense compactness below 30 $\mathrm{ft}$ depth. For the construction of low rise building, shallow foundation may be used with or without replacing the foundation soil layer by sand having proper compaction. For medium to high rise buildings, pile

\section{Acknowledgements}

I would like to show my gratitude to my supervisor Professor Dr. Keramat Ali Molla, Former Professor, Department of Civil Engineering, KUET who provided insight and expertise that greatly assisted the research.

I also thank to Director, CASR, and Khulna University of Engineering \& Technology for providing necessary data during the course of this research.

\section{References}

[1] Amadi, A. N., Eze, C. J., Igwe, C. O., Okunlola, I. A., \& Okoye, N. O. (2012). Architect's and geologist's view on the causes of building failures in Nigeria. Modern Applied Science, 6 (6), 31 -38 .

[2] Olabode, S. O., \& Adekoya, J. A. (2008). Seismic stratigraphy and development of Avon canyon in Benin (Dahomey) basin, southwestern Nigeria. Journal of African Earth Sciences, 50 (5), 286-304.

[3] Oke, S. A., \& Amadi, A. N. (2008). An Assessment of the Geotechnical Properties of the Subsoil of parts of Federal University of Technology, Minna, Gidan Kwano Campus, for Foundation Design and Construction. Journal of Science, Education and Technology, 1 (2), 87-102.

[4] Gulhati, S. K., \& Datta, M. (2005). Geotechnical Engineering Principles and Practices. Pearson Education Ltd.

[5] Amin, M. N., Kabir, M. H., Saha, G. P., \& Ahmed, M. (1987). "Geotechnical behaviour of soils from coastal region of Bangladesh.” Proc. 9th SEAGC, Bangkok, 7-11 Dec. V1 P5.1 5.12 .
[6] Hussain, M. M. (1980). Studies on the engineering properties of subsoil with reference to foundation requirements in the coastal area of Bangladesh. M.Sc. Engg. Thesis, Department of Civil Engineering, Bangladesh University of Engineering and Technology, Dhaka, Bangladesh.

[7] Shammi, M., Rahman, M. M., Bhuiya, G. M. J. A., Kamal, A. K. I., Rahman, M. R., \& Uddin, K. M., (2012). Investigation of Salinity Occurrences in Kumar-Madhumati River of Gopalganj District, Bangladesh. Journal of Nature Science and Sustainable Technology, 6, 299-314.

[8] Surendra, R. \& Sanjeev, K. B. (2017). Role of Geotechnical Properties of Soil on Civil Engineering Structures, Resources and Environment, 7 (4), 103-109.

[9] Dutta, S., \& Barik, D. (2009). Studies on geotechnical properties of subsoil in south east coastal region of India. IOP Conference Series: Materials Science and Engineering, 263.

[10] Nwankwoala, H. O., Amadi, A. N., Ushie F. A., Warmate, T. A., \& Eze, C. J. (2014). Determination of Subsurface Geotechnical Properties for Foundation Design and Construction in Akenfa Community, Bayelsa State, Nigeria. American Journal of Civil Engineering and Architecture, 2 (4), 130-135.

[11] Oke, S. A., Okeke, O. E., Amadi, A. N., \& Onoduku, U. S. (2009). Geotechnical Properties of the Subsoil for Designing Shallow Foundation in some selected parts of Chanchaga area, Minna, Nigeria. Journal of Environmental Science, 1 (1), 45 54.

[12] Layade, G. O., \& Ogunkoya, C. O. (2018). Geotechnical properties of lateritic soil as subgrade and base material for road construction in Abeokuta, Southwest Nigeria. International Journal of Advanced Geosciences, 6 (1), 78-82.

[13] Łukasz, A. K., Maciej, K. K., \& Monika, K. (2017). Geotechnical parameters of soil, considering the effect of additional compaction of embankment. Transportation Geotechnics and Geoecology, Procedia Engineering 189, 291 297.

[14] Zadroga, B. (2010). Methodology of determination of geotechnical parameters for non-cohesive soils based on dynamic and static penetration test. 4th International Workshop. Uniwersytetu Przyrodniczego w Poznaniu, 543-551.

[15] Meyer, Z. (2013). Static load tests, shorts series interpretation, XVI French Polish Colloquium of Soil and Rock Mechanics. Montpellier France. 